\title{
Y-Box Binding Protein 1 Expression in Trophoblast Cells Promotes Fetal and Placental Development
}

\author{
Nicole Meyer ${ }^{1,2, \dagger}{ }^{,}$Anne Schumacher ${ }^{1,2,+}$, Urs Conen $^{1}$, Katja Woidacki ${ }^{1}$, Hannah Schmidt ${ }^{1}$, \\ Jonathan A. Lindquist ${ }^{3}$ (D) , Peter R. Mertens ${ }^{3}$ and Ana C. Zenclussen ${ }^{1,2, *}$ \\ 1 Experimental Obstetrics and Gynecology, Medical Faculty, Otto-von-Guericke University, \\ 39108 Magdeburg, Germany; nicole.meyer@med.ovgu.de (N.M.); anne.schumacher@med.ovgu.de (A.S.); \\ urs.coenen@outlook.com (U.C.); katja.woidacki@med.ovgu.de (K.W.); Hannah.Schmidt.HS@posteo.de (H.S.) \\ 2 Department of Environmental Immunology, Helmholtz Centre for Environmental Research, \\ 04318 Leipzig, Germany \\ 3 Department of Nephrology and Hypertension, Diabetes and Endocrinology, Otto-von-Guericke University, \\ 39120 Magdeburg, Germany; jon.lindquist@med.ovgu.de (J.A.L.); peter.mertens@med.ovgu.de (P.R.M.) \\ * Correspondence: ana.zenclussen@ufz.de; Tel.: +49-341-235-1265 \\ + These authors contributed equally to this work.
}

Received: 27 July 2020; Accepted: 21 August 2020; Published: 22 August 2020

check for

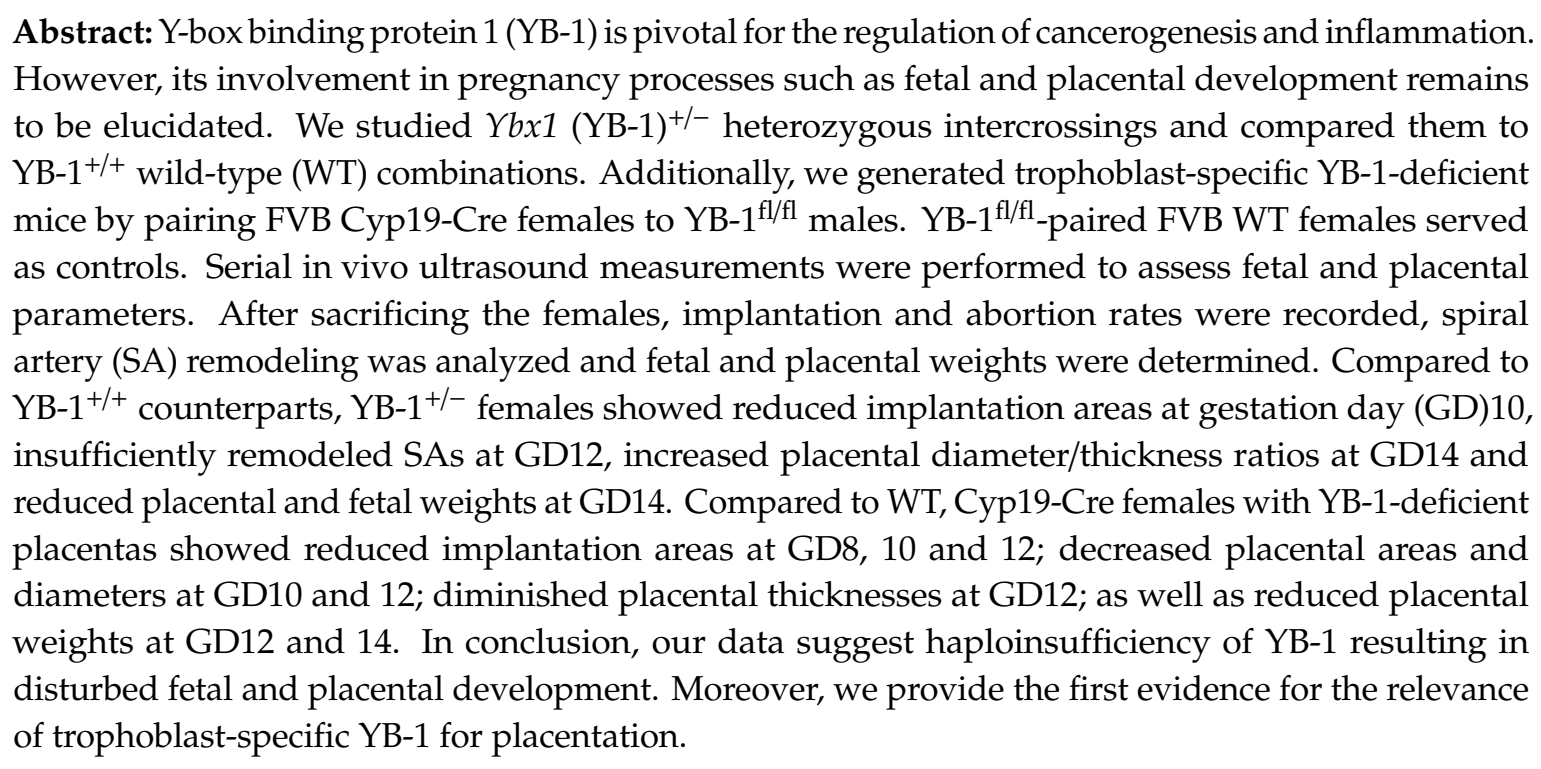
Keywords: Y-box binding protein 1; trophoblast; fetal and placental development; pregnancy; serial high-frequency ultrasonography

\section{Introduction}

Y-box binding protein 1 (YB-1) is a multifunctional cold shock protein that regulates a variety of biological processes including transcriptional and translational control at cellular level. In the nucleus, YB-1 participates in DNA repair and replication mechanisms as well as in gene transcription. In the cytoplasm, YB-1 regulates mRNA translation and protects the mRNA from degradation. A detailed overview of YB-1 functions is provided in Reference [1]. Moreover, in response to inflammatory stimuli and oxidative insults, YB-1 is actively secreted by different cell types and exerts its autocrine and paracrine effects on various target cells $[2,3]$.

Pregnancy is arguably the most critical period in every individual's life, as the events occurring in the maternal womb shape adult health $[4,5]$. During this period, timely and finely regulated interactions 
between the maternal and fetal tissues not only guarantee the survival of the genetically foreign fetus, but also actively support its adequate development. The complex network between maternal and fetal structures is built up by a plethora of molecules whose expression is strictly controlled at distinct gestational ages. Thus, knowing the pivotal functions of YB-1 in regulating gene expression, it is conceivable that YB-1 plays a major role in fundamental pregnancy processes, such as fetal and placental development. Notably, YB-1 is expressed during almost the entire ontogenesis, particularly in its early stages [6]. Its presence has been proven in mouse embryonic stem cells [7], and embryonic day (E)13.5 embryos show an almost ubiquitous expression of YB-1 with the highest expression in the central nervous system, lung, kidney and heart [8]. In 2005, Lu and colleagues were the first to develop an YB-1 loss-of-function mouse model and provide evidence for a nonredundant role of YB-1 in late embryonic development and perinatal survival of the pups. These authors showed that most Ybx1 (from now on, YB-1) -knockout (KO) embryos developed normally until E13.5, but exhibited severe growth retardation and mortality thereafter. Only a few YB-1 KO fetuses were born, albeit they died shortly after birth. Detailed analyses of the KO embryos revealed neurological lesions, severe hemorrhages and respiratory failures, and it was suggested that these malformations at least partially accounted for the perinatal lethality [9]. One year later, Uchiumi and colleagues also performed YB-1 heterozygous intercrossings and found YB-1 KO embryos to be growth-retarded as early as E10.5. Furthermore, the authors showed that YB-1-deficient embryos die between E14.5 and E18.5. In their hands, YB-1 KO embryos showed hemorrhages, severe anemias and severe brain malformations, but were otherwise normal in appearance [8]. As YB-1 is a key molecule in transcriptional and translational regulation, both research groups assumed changes in the transcriptome and proteome of embryonic fibroblasts from YB-1-deficient embryos. Remarkably, YB-1-deficient embryonic fibroblasts did not exhibit major changes in either cellular process, but showed an enhanced sensitivity to different stressors as well as a reduced ability to grow and divide $[8,9]$.

It has been speculated that late embryonic hypoplasia as consequence of an YB-1 deficiency might derive from a placental defect [10]. Although no detailed analysis regarding placental structure and function was performed, it was obvious that YB-1 KO placentas were smaller than YB-1-sufficient placentas [9]. A smaller placental volume often goes hand in hand with suboptimal function; this can in turn impair fetal growth, wellbeing and survival. Therefore, it is imperative to address this issue in more detail to understand the possible implications in pregnancy complications and suboptimal fetal development.

For certain cancer types, YB-1 has been reported to promote cell proliferation [11,12], migration and invasion $[13,14]$, as well as to inhibit apoptosis $[15,16]$. All of these mechanisms are in the repertoire of trophoblast activity and hence they are critical for adequate placental development. However, whether YB-1 affects trophoblast function remains to be elucidated. Supportive evidence for an involvement of YB-1 in placentation might be derived from the fact that, in vitro, YB-1 is able to induce matrix metalloproteinases (MMPs) $[17,18]$. These enzymes are capable of cleaving components of basal membranes and are therefore strongly involved in extensive tissue remodeling processes during placenta formation $[19,20]$. To follow up the idea of a potential participation of YB-1 in placentation and fetal development, we undertook the present study, with the aims of understanding whether YB-1 affects trophoblast functions and to evaluate whether trophoblast-derived YB-1 is crucial for placentation and fetal growth. For this, we first studied maternal and fetal parameters in YB-1 heterozygous intercrossings. After finding that fetal and placental growth as well as spiral artery (SA) remodeling was negatively affected by the partial or total absence of YB-1, we next generated trophoblast-specific YB-1-deficient mice to understand its impact in placenta physiology, fetal growth and fetal survival until day 14 of gestation. Placenta-specific YB-1 knockdown resulted in decreased placental areas, diameters, thicknesses and weights, but did not affect fetal weights. 


\section{Materials and Methods}

\subsection{Mice}

Male and female C57BL/6 wild-type (WT, thus YB-1 ${ }^{+/+}$) and heterozygous (HET, YB-1 ${ }^{+/-}$) YB-1 mice were bred and maintained at our barrier facility. FVB Cyp19-Cre (5912 line) and floxed C57BL/6 YB-1 (YB-1 ${ }^{\mathrm{fl} / \mathrm{fl}}$ ) mice were kindly provided by the groups of Prof. Leone (Ohio State University, Columbus, $\mathrm{OH}, \mathrm{USA}$ ) and Prof. Mertens (Magdeburg University, Magdeburg, Germany), respectively. Using these strains, we generated mice with trophoblast-specific YB-1 deficiency. FVB Cyp19-Cre females were mated to $\mathrm{YB}-1^{\mathrm{fl} / \mathrm{fl}}$ males and vice versa. As both mating combinations showed comparable results concerning their implantation and abortion rates, we focused our analyses on YB- ${ }^{\mathrm{fl} / \mathrm{fl}}$-mated Cyp19-Cre females. Female FVB WT mice were purchased from Janvier, Le Genest-Saint-Isle, France. All mice were kept in a $12 \mathrm{~h}$ light/dark cycle at $22 \pm 2{ }^{\circ} \mathrm{C}$ and an air humidity of $40-60 \%$. Mice received water and food ad libitum.

\subsection{Experimental Design and Sample Collection}

Animal experiments were performed according to the institutional guidelines upon ministerial approval (Landesverwaltungsamt Sachsen-Anhalt: 42502-2-1327 Uni MD). All experiments were conducted by authorized persons according to the Guide for Care and Use of Animals in Agriculture Research and Teaching. Eight- to eleven-week-old YB-1 ${ }^{+/-}$females were paired with YB- $1^{+/-}$males. $\mathrm{YB}-1^{+/+}$females paired with $\mathrm{YB}-1^{+/+}$males served as controls. In further experiments, FVB Cyp19-Cre or WT females were paired with YB-1 $1^{\mathrm{fl} / \mathrm{fl}}$ males to obtain trophoblast-specific YB-1 knockdown animals or floxed controls, respectively. Females were checked twice a day for the appearance of a vaginal plug. Plug detection indicated gestation day (GD)0 of pregnancy. Serial in vivo ultrasound measurements were performed at GD5, 8, 10, 12 and 14. Animals were sacrificed at GD10, 12 or 14. Numbers of implantations and abortions were recorded. For SA analysis, one implantation per female was dissected at GD12 and fixed as explained elsewhere [21]. At GD12 and 14, fetal and placental weights were determined.

\subsection{High-Frequency Ultrasound Measurement}

Serial ultrasound examinations were performed using the Vevo ${ }^{\circledR} 2100$ system (FujiFilm VisualSonics Inc., Amsterdam, The Netherlands) as described previously [22,23]. Briefly, mice were anesthetized with isoflurane, transferred and fixed to a heating platform and abdominal hair was removed with a depilatory cream. Eyes were protected from drying out by applying eye protection cream. Prewarmed ultrasound gel was applied on the abdomen, and ultrasound measurements were done with the transducer MS550D (22-55 MHz). Implantation areas (GD5, 8, 10, 12), as well as placental areas, thicknesses, and diameters (GD10, 12, 14) were measured in B-Mode. Color Doppler Mode and the Pulse-wave Doppler Mode were used to determine blood flow parameters in the maternal uterine arteries (GD5, 8, 10, 12, 14). With the Vevo LAB software, peak systolic velocities (PSVs) and end diastolic velocities (EDVs) were recorded (average of three measurements) and resistance indices $(\mathrm{RI} ; \mathrm{RI}=(\mathrm{PSV}-\mathrm{EDV}) / \mathrm{PSV})$ and pulsatility indices $(\mathrm{PI}$; PI $=($ Velocity $(\mathrm{V}) \mathrm{max}-\mathrm{Vmin}) / \mathrm{Vmean})$ were calculated. During ultrasound measurement, ECG, body temperature and respiratory physiology of the mice were controlled throughout.

\subsection{Measurement of Fetal and Placental Weights}

Fetal and placental weights were determined at GD12 and 14 using a scale (Kern \& Sohn GmbH, Balingen, Germany, minimum: $0.02 \mathrm{~g}$, sensitivity: $0.001 \mathrm{~g}$ ). 


\subsection{Histology}

Implantations were fixed for $6 \mathrm{~h}$ in a $4 \%$ paraformaldehyde (PFA) solution containing $0.1 \mathrm{M}$ saccharose ( $\mathrm{pH}$ 7.4) by gently shaking at room temperature. Afterwards, they were stored overnight at $4{ }^{\circ} \mathrm{C}$ in $70 \%$ ethanol. The following day, implantations were cut into two halves, dehydrated through an ascending ethanol series, incubated in xylene and embedded in paraffin. Five-micrometer paraffin sections were stained with hematoxylin and eosin (H/E). H/E staining was performed as previously described [21].

\subsection{Spiral Artery Analysis}

SA parameters were analyzed in H/E-stained implantation sections at GD12. We collected one implantation site per female and subsequently analyzed 3-10 SAs, localized in the decidua basalis within the implantation site, via light microscope (Zeiss, Jena, Germany, 200× magnification). With the AxioVision software v4 (Zeiss), wall and lumen perimeters of SAs were measured to calculate wall and lumen diameters $($ diameter $=$ circumference $/ \pi$ ) and wall-to-lumen ratios (wall-to-lumen ratio $=\mathrm{SA}$ diameter/diameter lumen). The wall thickness was calculated ((SA diameter - lumen diameter)/2). Mean wall thicknesses and wall-to-lumen ratios were calculated for each female.

\subsection{Statistics}

GraphPad Prism 8.0 (Statcon GmbH, Witzenhausen, Germany) and SPSS Statistics 26.0 (IBM, Leipzig, Germany) were used for the statistical analysis of the data. Normality of the data was assessed with the D' Agostino Pearson-Omnibus test. Data was analyzed by using the Mann-Whitney- $U$ test (GraphPad Prism, Statcon GmbH) or a mixed linear model using the final test principle (SPSS, IBM, Leipzig, Germany). Data is presented as medians or means with standard deviation (SD). $p$ values $<0.05$ were considered to be statistically significant.

\section{Results}

\subsection{YB-1 Deficiency Negatively Affected Implantation and Fetal Growth}

To understand the participation of YB-1 in pregnancy outcome based on implantation and abortion rates, HET $\left(\mathrm{YB}-1^{+/-} \mathrm{x}\right.$ YB-1 $\left.{ }^{+/-}\right)$mating combinations were analyzed, with resulting $\mathrm{WT}\left(\mathrm{YB}-1^{+/+}\right)$,

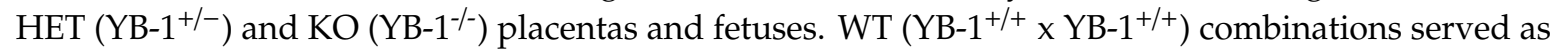
controls. Neither partial nor total deficiency in placental tissue affected the number of implantations or abortion (Table 1).

Table 1. YB-1 deficiency did not affect implantation and abortion rates.

\begin{tabular}{ccc}
\hline Measurement & YB-1 $^{+/+} \times \mathbf{Y B}^{+/++}$ & $\mathbf{Y B}^{+\mathbf{1}^{+/-}} \times \mathbf{Y B}^{\mathbf{H}-/-}$ \\
\hline Number of implantations & $10(3-12)$ & $10(9-11)$ \\
Number of abortions & $2(0-3)$ & $1(0-3)$ \\
Abortion rate $(\%)$ & $18.13(0.00-100)$ & $10.56(10-27.27)$ \\
\hline
\end{tabular}

Analysis included YB- $1^{+/+}$females $(n=10)$ and YB- $1^{+/-}$females $(n=10)$, mated to $\mathrm{YB}^{+/++}$or YB $-1^{+/-}$males, respectively. Data sets represent combined data from GD12 $(n=5$ per mating combination) and GD14 $(n=5$ per mating combination). Data is shown as the medians plus range. Statistical analysis was performed with the Mann-Whitney- $U$ test.

Next, serial high-frequency ultrasound examinations were performed during gestation of YB- $1^{+/+}$ and YB-1 ${ }^{+/-}$females to follow fetal growth in vivo. For this, the size of whole implantations were analyzed. At GD5 and GD8, no differences were detected among the maternal genotypes. This changed as pregnancy advanced, with implantation areas of $\mathrm{YB}-1^{+/-}$females being significantly reduced $(p<0.05)$ at GD10 compared to YB-1 ${ }^{+/+}$control females at the same gestational point (Figure 1A). 
Representative 2D greyscale images showing whole implantations from $\mathrm{YB}-1^{+/+}$(i-iii) or $\mathrm{YB}-1^{+/-}$ (iv-vi) females are displayed in Figure 1B.

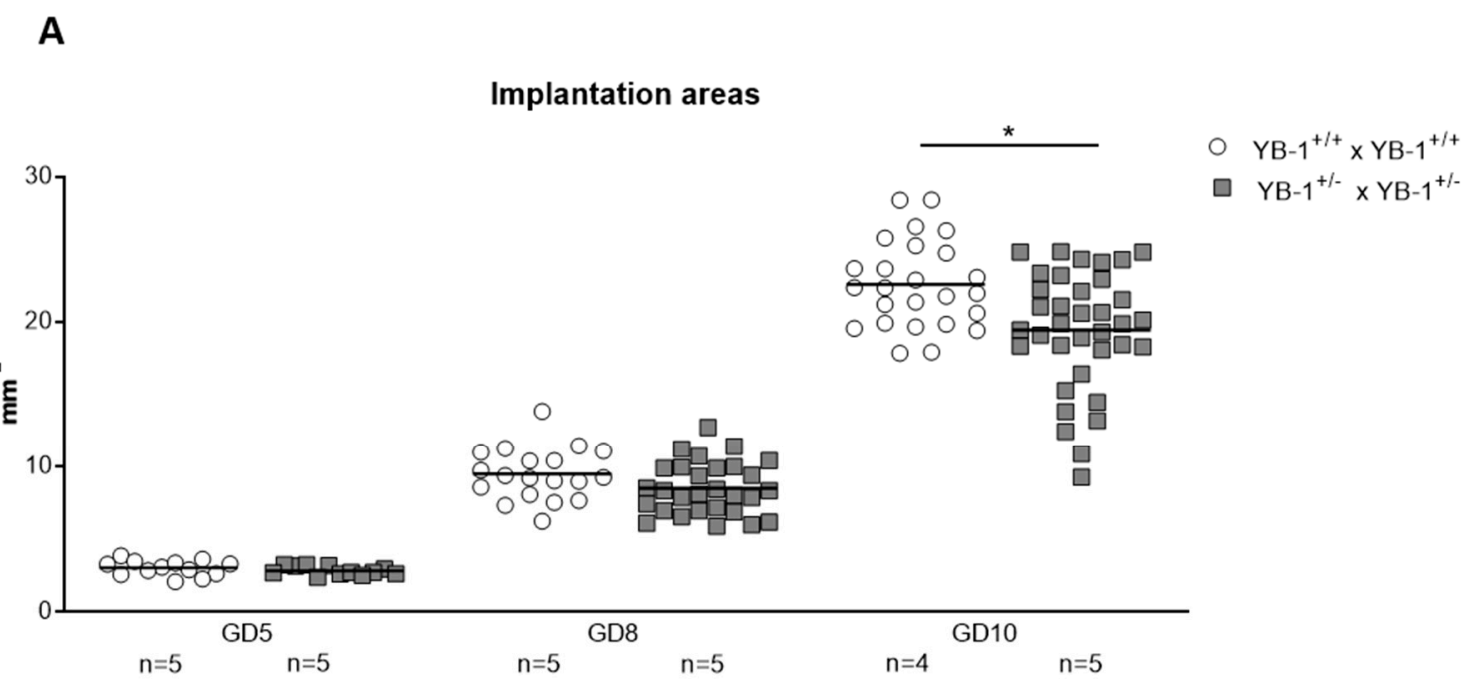

B
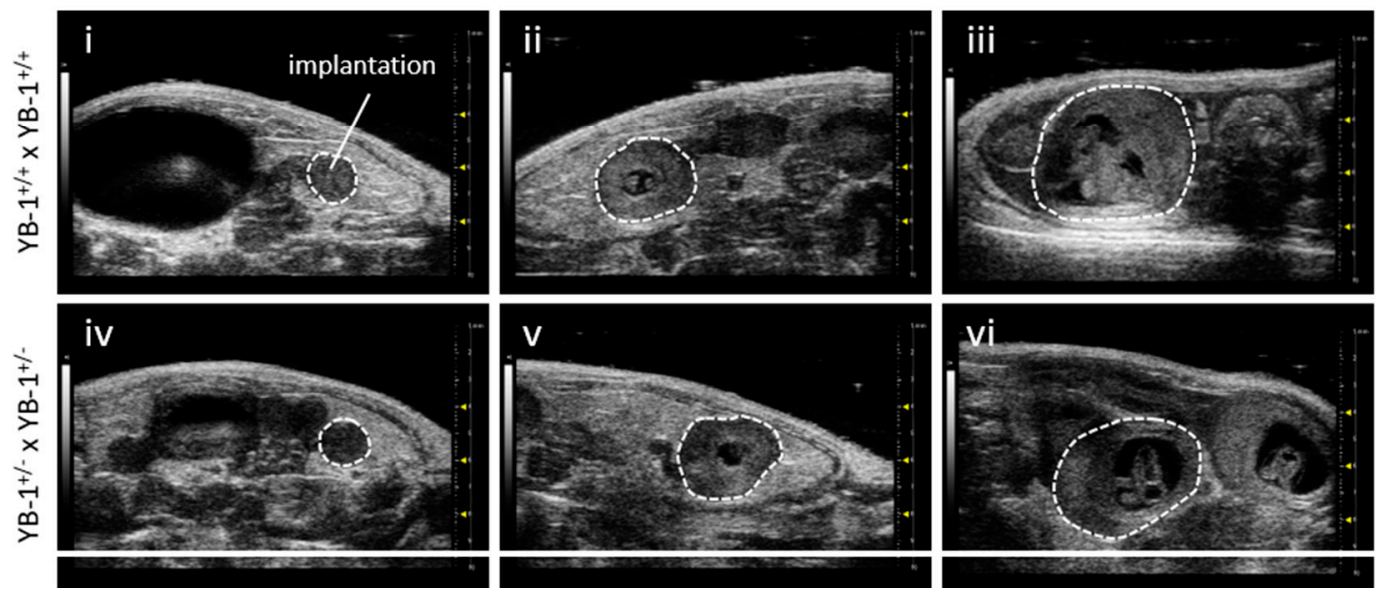

Figure 1. Decreased implantation areas in pregnant $\mathrm{YB}-1^{+/-}$females compared to $\mathrm{YB}-1^{+/+}$females at GD10. (A) Implantation areas of single implantations of YB- $1^{+/+} \times \mathrm{YB}-1^{+/+}(n=4-5)$ or $\mathrm{YB}-1^{+/-} \times$ $\mathrm{YB}^{+} 1^{+-}(n=5)$ matings at GD5, 8 , and 10. The data is presented as medians showing individual values for each implantation site. Statistical differences between both mating combinations per time point were determined by using a mixed linear model using the final test principle $\left({ }^{*} p<0.05\right)$. (B) Representative 2D greyscale ultrasound images at GD5 (i, iv), 8 (ii, v), and 10 (iii, vi) from YB-1 WT (i-iii) and YB-1 HET (iv-vi) matings are shown.

\subsection{YB-1 Deficiency Altered Fetal and Placental Parameters}

Diminished implantation areas as observed in fetuses from $\mathrm{YB}-1^{+/-}$females might be a consequence of impaired placental and/or fetal growth. To analyze whether YB-1 is pivotal for placental growth, serial ultrasound measurements were performed to assess the following placental parameters: area, thickness and diameter (Figure S1). All three placental parameters (Figure 2A-C) were comparable between YB-1 WT and HET mating combinations for the analyzed time points GD10, 12 and 14. However, placental diameter/thickness ratios that are strong indicators of placental insufficiency, were significantly increased $(p<0.05)$ in $\mathrm{YB}-1^{+/-}$females compared to $\mathrm{YB}-1^{+/+}$females (Figure 2D). 
A

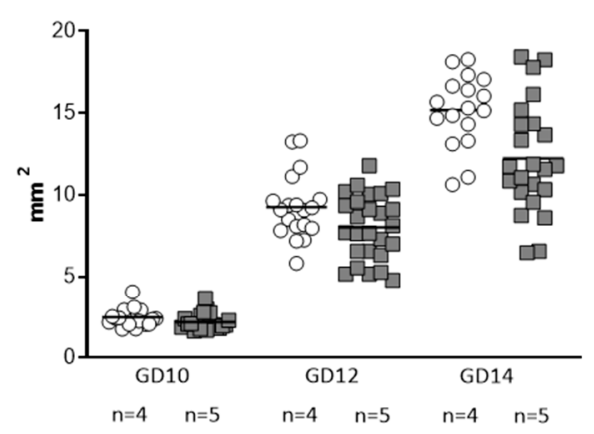

C

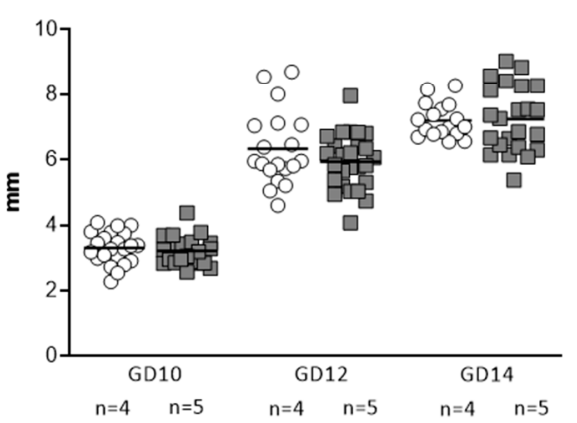

B Placental thicknesses

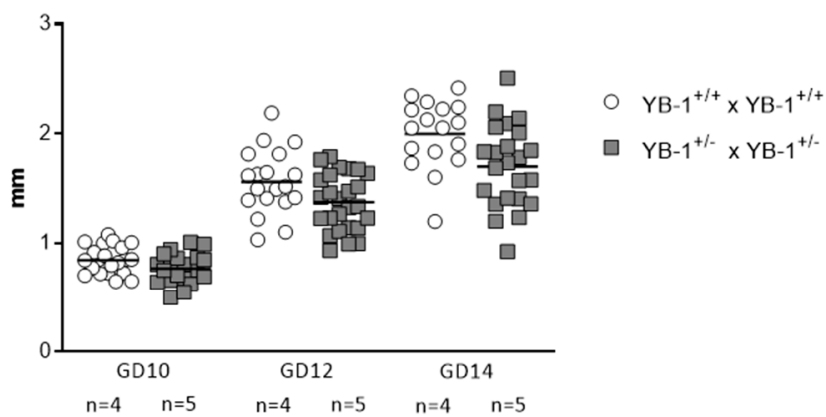

D

PD/PT ratios

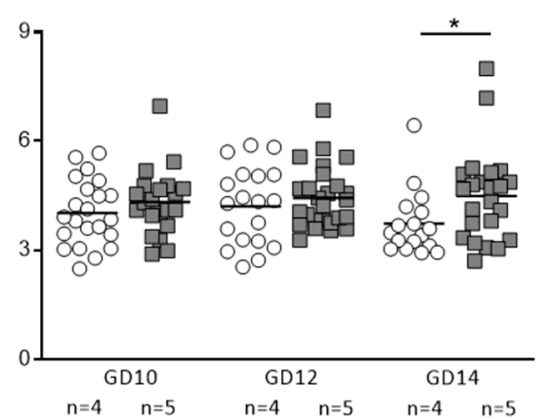

Figure 2. Significant increased placental diameter/thickness ratios in pregnant $\mathrm{YB}-1^{+/-}$compared to $\mathrm{YB} \mathrm{1}^{+/+}$females at GD14. Placental areas (A), thicknesses (B), diameters (C) and diameter/thickness $(\mathrm{PD} / \mathrm{PT})$ ratios $(\mathrm{D})$ of $\mathrm{YB}-1^{+/+} \times \mathrm{YB}-1^{+/+}(n=4)$ and $\mathrm{YB}-1^{+/-} \times \mathrm{YB}-1^{+/-}(n=5)$ matings are displayed at GD10, 12 and 14. Placental parameters are presented as medians showing individual values for each placenta. Statistical differences were determined by using a mixed linear model using the final test principle $\left({ }^{*} p<0.05\right)$.

While placental and fetal weights were comparable at GD12 (Figure 3A,C), YB-1 HET females presented significantly reduced placental and fetal weights at GD14 compared to their $\mathrm{YB}-1^{+/+}$ counterparts (Figure 3B,D). 
A

Placental weights GD12

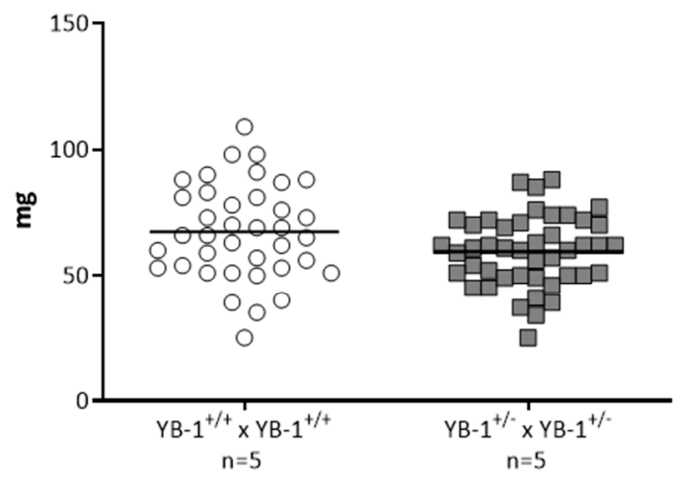

C

Fetal weights GD12

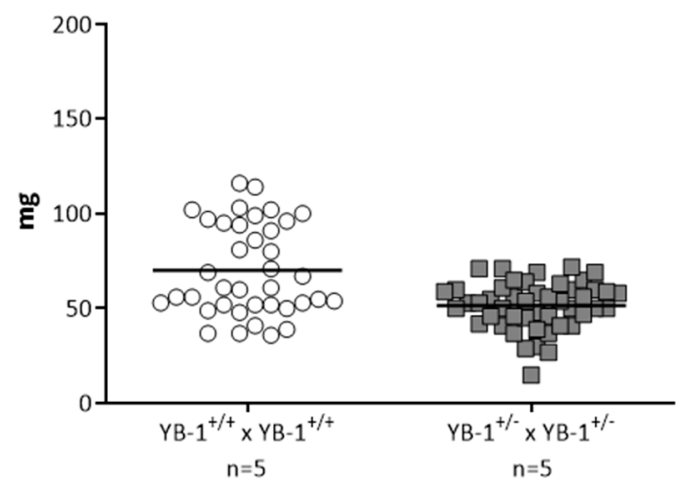

B

Placental weights GD14

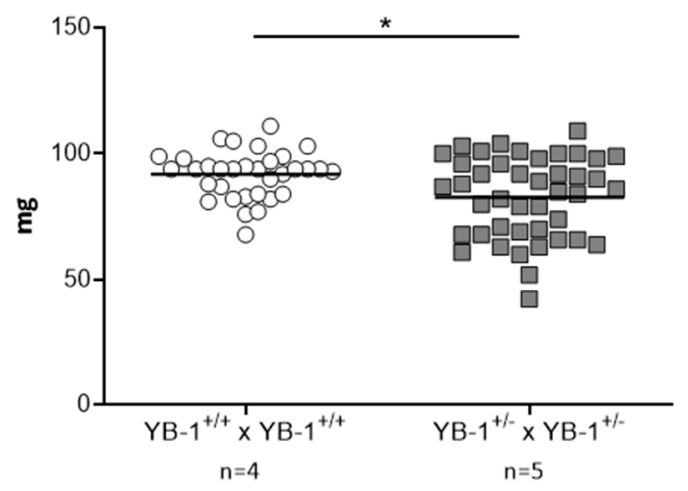

D

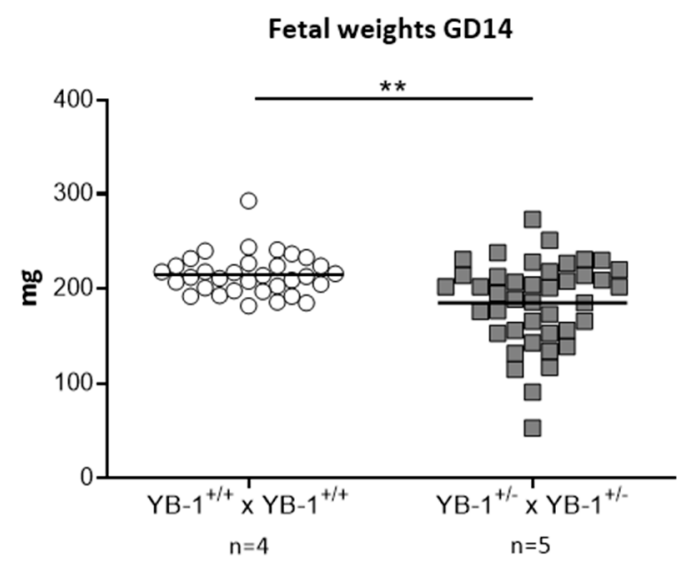

Figure 3. Significant decreased placental and fetal weights in $\mathrm{YB}-1^{+/-}$females compared to $\mathrm{YB}-1^{+/+}$ females at GD14. Placental weights $(\mathbf{A}, \mathbf{B})$ and fetal weights $(\mathbf{C}, \mathbf{D})$ from the progeny of $\mathrm{YB}-1^{+/+} \times$

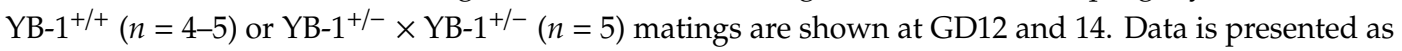
medians showing individual values for each fetus/placenta. Statistical differences were determined by using a mixed linear model using the final test principle $\left({ }^{*} p<0.05 ;{ }^{* *} p<0.01\right)$.

3.3. Placental YB-1 Deficiency Resulted in Impaired Remodeling of Uterine Spiral Arteries without Affecting Uterine Artery Flow Parameters

Next, we focused on the analysis of the remodeling process that takes place during placentation in the maternal uterus and is crucial for fetal growth. During this process, uterine SAs are modified from low-flow, high-resistance to high-flow, low-resistance vessels capable of fulfilling the demands of the developing fetus [24]. YB-1 ${ }^{+/-}$females showed insufficiently remodeled SAs when compared to $\mathrm{YB}-1^{+/+}$females. More precisely, as a signature of inadequately and incompletely remodeled SA, there was a significantly higher $(p<0.05)$ wall thickness (Figure $4 \mathrm{~A})$, resulting in a higher $(p<0.05)$ and thus pathologic wall-to-lumen ratio (Figure $4 \mathrm{~B}$ ) in $\mathrm{YB}^{+1 /-}$ females compared to WT control females. Representative pictures of WT matings (i) and HET matings (ii) are shown in Figure 4C. As a consequence of insufficiently remodeled SAs, hemodynamic alterations can be expected in these vessels. Accordingly, the peak systolic and end diastolic velocity (Figure S2) were determined to calculate the PI and RI at GD10, 12, and 14 (Figure S2B,C). However, both indices indicative for the uterine blood flow were not changed when YB-1 was reduced. 
A

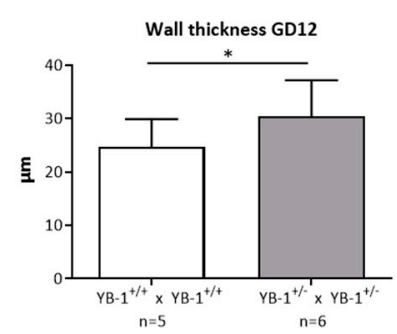

B

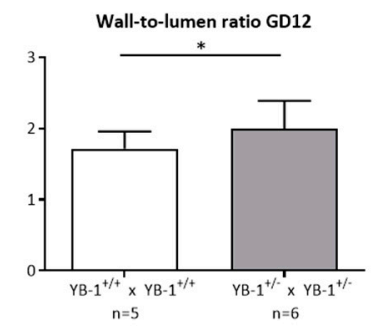

C
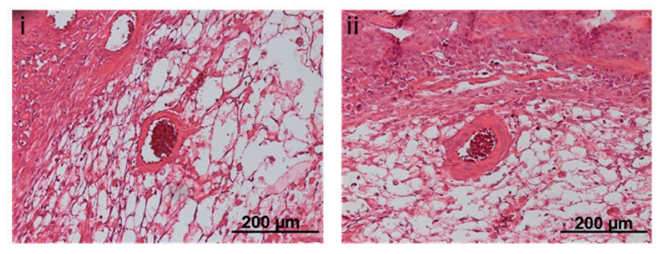

Figure 4. Impaired SA remodeling in $\mathrm{YB}-1^{+/-}$females compared to $\mathrm{YB}-1^{+/+}$females at GD12. Wall thicknesses (A) and wall-to-lumen ratios (B) of YB- $1^{+/+} \times$YB- $1^{+/+}(n=5)$ or YB-1 $1^{+/-} \times$YB- $1^{+/-}(n=6)$ matings are displayed at GD12. Results are presented as means with standard deviation (SD) and analyzed by using a mixed linear model using the final test principle $(* p<0.05)$. (C) Representative hematoxylin/eosin-stained slides of implantations showing uterine spiral arteries (SAs) in the decidua basalis of YB-1 $1^{+/+}$(i) and YB-1+/- (ii) females at GD12 (scale bar $=200 \mu \mathrm{m}$ ).

\subsection{Trophoblast-Specific YB-1 Deficiency Negatively Affected Fetal and Placental Parameters with a Phenotype} of Decreased Placental Weight

Next, we wondered whether YB-1 expressed in trophoblasts regulates critical functions in fetal and placental growth. To answer this relevant question, we generated trophoblast-specific YB-1-deficient mice by mating Cyp19-Cre females with YB-1 $1^{\mathrm{fl} / \mathrm{fl}}$ - males. Controls included YB-1 $1^{\mathrm{f} / \mathrm{fl}}$-mated WT females. Our results revealed that trophoblast-specific YB-1 ablation had no effect on implantation number and fetal survival as analyzed in pregnant females at GD10, 12 and 14 (Table 2).

Table 2. YB-1 deficiency in trophoblast cells did not affect implantation and abortion rates.

\begin{tabular}{ccc}
\hline Measurement & WT $\times \mathbf{Y B}^{\mathbf{f}} \mathbf{f}^{\mathbf{f} / \mathbf{f l}}$ & Cyp19-Cre $\times \mathbf{Y B}^{\mathbf{f}} \mathbf{f} / \mathbf{f l}$ \\
\hline Number of implantations & $11(1-13)$ & $9(2-14)$ \\
Number of abortions & $0(0-3)$ & $1(0-3)$ \\
Abortion rate $(\%)$ & $0.00(0.00-23.08)$ & $11.11(0.00-50.00)$ \\
\hline
\end{tabular}

Analysis included WT females $(n=13)$ and Cyp19-Cre females $(n=15)$ mated to YB-1 $1^{\mathrm{f} / \mathrm{fl}}$ males. Data sets represent combined data from GD10 ( $n=3$ per mating combination), GD12 ( $n=7$ or 9 per mating combination) and GD14 ( $n=3$ per mating combination). Data is shown as medians plus range. Statistical analysis was performed with the Mann-Whitney- $U$ test.

Even though the number of implantation and surviving fetuses did not seem to be affected, serial high-frequency ultrasound examinations revealed that the absence of trophoblast-derived YB-1 resulted in significantly reduced $(p<0.001)$ implantation areas at GD8, 10 and 12 (Figure 5A). Representative 2D greyscale images are shown of WT (i-iv) and Cyp19-Cre (v-viii) females in Figure 5B. 
A Implantation areas

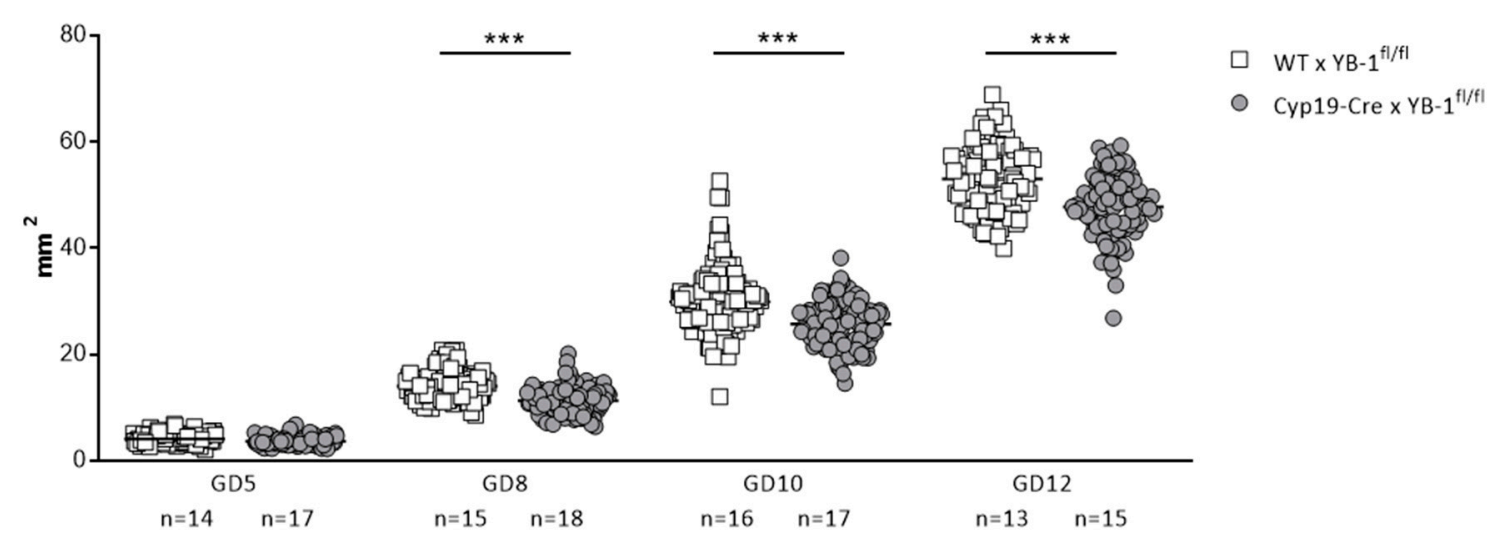

B

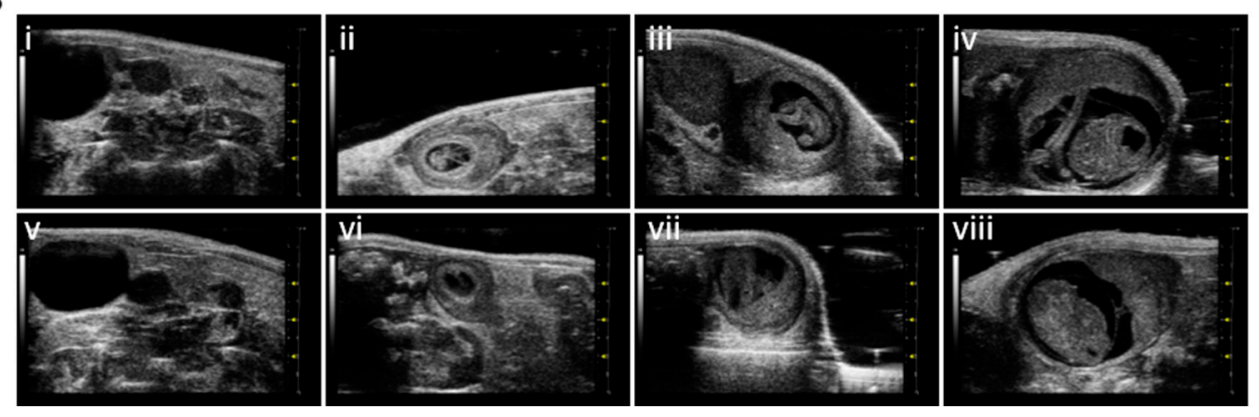

Figure 5. Decreased implantation areas in $\mathrm{YB}-1^{\mathrm{f} / \mathrm{fl}}$-mated Cyp19-Cre females compared to YB-1 $\mathrm{C}^{\mathrm{f} / \mathrm{fl}}$-mated WT females from GD8 onwards. (A) Implantation areas of single implantations of Cyp19-Cre x YB- $1^{\mathrm{fl} / \mathrm{fl}}(n=6-16)$ or WT x YB-1 ${ }^{\mathrm{fl} / \mathrm{fl}}(n=6-18)$ matings at GD5, 8, 10 and 12. Results are presented as means showing individual values for each implantation. Statistical differences were determined by using a mixed linear model using the final test principle $\left.{ }^{* * *} p<0.001\right)$. (B) Representative 2D greyscale ultrasound images at GD5 (i, v), 8 (ii, vi), 10 (iii, vii) and 12 (iv, viii) from WT $\times$ YB-1 $1^{\mathrm{fl} / \mathrm{fl}}$ (i-iv) and Cyp19-Cre $\times$ YB-1 $1^{\mathrm{fl} / \mathrm{fl}}$ (v-viii) matings.

Moreover, placental areas $(p<0.05, p<0.01)$ and placental diameters $(p<0.05)$ were significantly decreased in Cyp19-Cre females mated to YB-1 $1^{\mathrm{f} / \mathrm{fl}}$ males compared to WT females mated to YB-1 $1^{\mathrm{fl} / \mathrm{fl}}$ males at GD10 and 12 (Figure 6A,C). Accordingly, placental thicknesses were significantly diminished $(p<0.05)$ at GD12 (Figure 6B), regardless of the fact that placental diameter/thickness ratios were not significantly affected by trophoblastic YB-1 ablation (Figure 6D). 

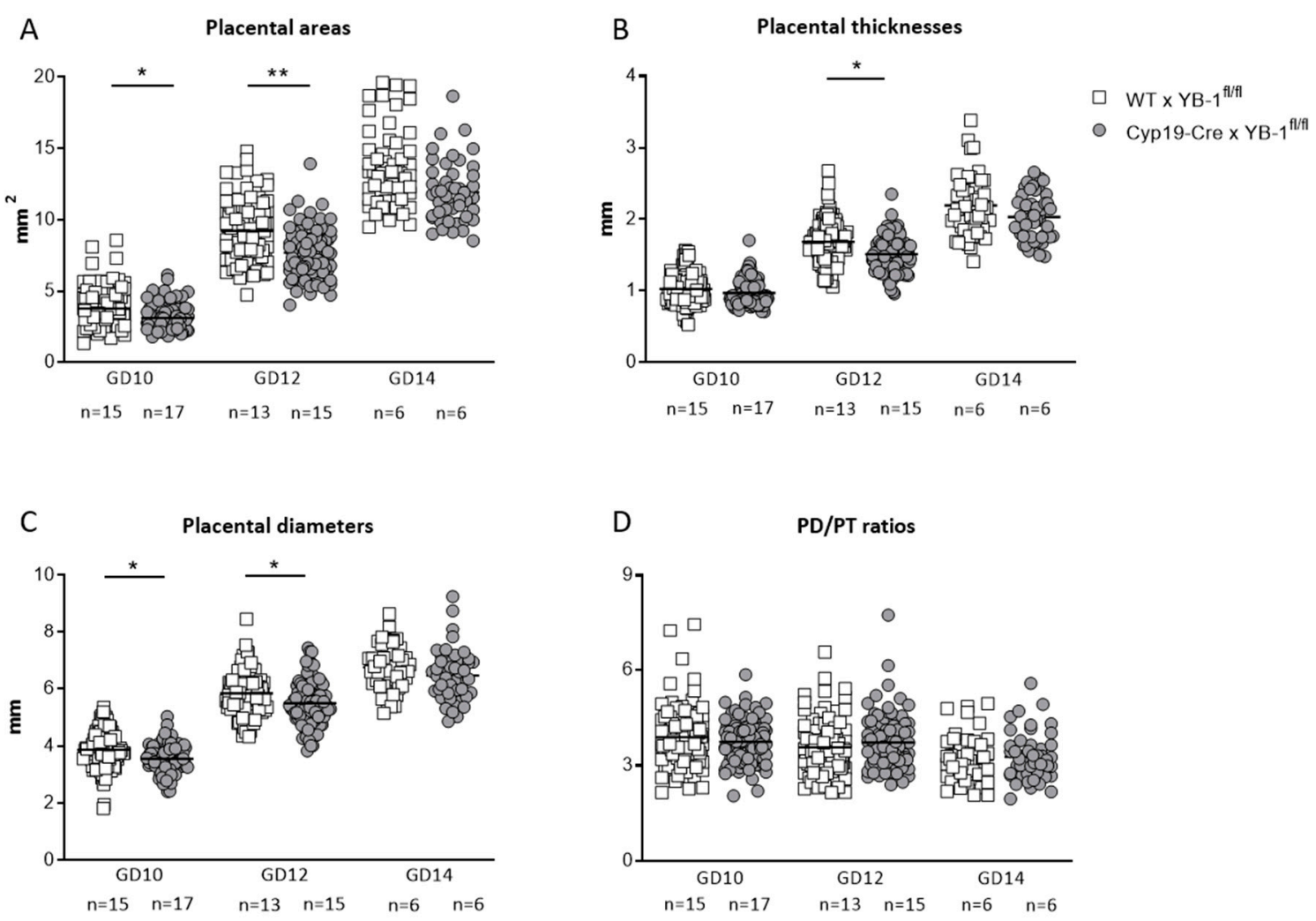

Figure 6. Altered placental parameters in $\mathrm{YB}-1^{\mathrm{fl} / \mathrm{fl}}$-mated Cyp19-Cre females compared to $\mathrm{YB}-1^{\mathrm{fl} / \mathrm{fl}}$-mated WT females at GD14. Placental areas (A), thicknesses (B), diameters $(\mathbf{C})$ and diameter/thickness (PD/PT) ratios $(\mathrm{D})$ of Cyp19-Cre $\times$ YB-1 $1^{\mathrm{fl} / \mathrm{fl}}(n=6-15)$ or $\mathrm{WT} \times \mathrm{YB}^{\mathrm{fl}}{ }^{\mathrm{fl} f \mathrm{fl}}(n=6-17)$ matings are displayed at GD10, 12 and 14. Placental parameters are presented as means showing individual values for each placenta. Statistical differences were determined by using a mixed linear model using the final test principle $\left({ }^{*} p<0.05 ;{ }^{* *} p<0.01\right)$.

In line with the results obtained in heterozygous combinations, YB-1 deficiency in trophoblast cells did not alter uterine artery flow parameters. More precisely, uterine artery PI and RI were comparable between both mating combinations at GD5, 8, 10, 12 and 14 (Figure S3B,C). Both indices were calculated based on the determination of the peak systolic and end diastolic velocities (Figure S3A). Finally, we analyzed whether trophoblast-derived YB-1 is pivotal for placental and fetal growth. For this, fetal and placental weights were recorded at GD12 and 14. Placental weights were significantly lower $(p<0.05)$ in $\mathrm{YB}-1^{\mathrm{fl} / f \mathrm{fl}}$-mated Cyp19-Cre females when compared to YB-1 $1^{\mathrm{fl} / \mathrm{fl}}$-mated WT females at GD12 and 14 (Figure 7A,B) with no significant differences in fetal weights at the same gestation day (Figure 7C,D). 
A

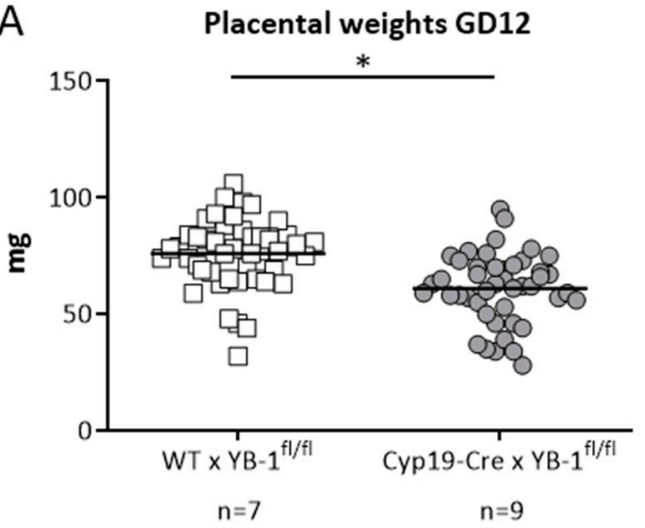

C

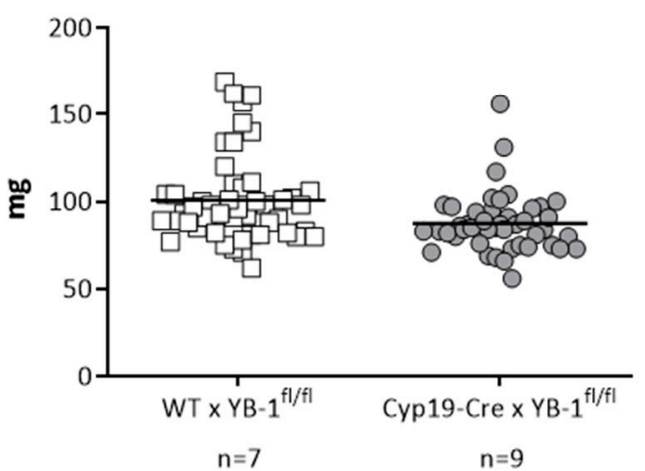

B

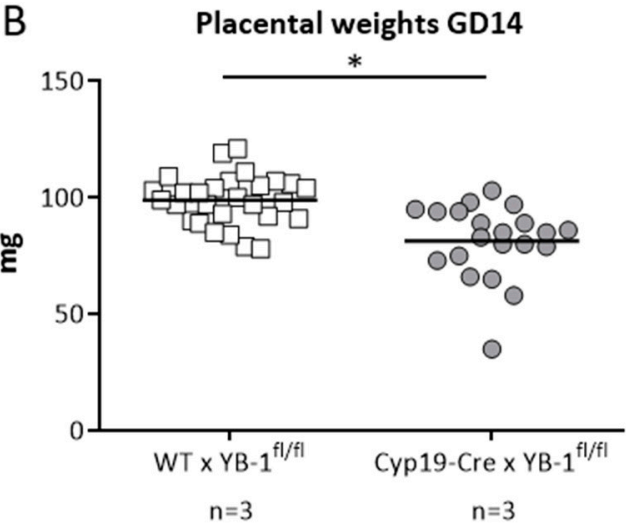

D

Fetal weights GD14

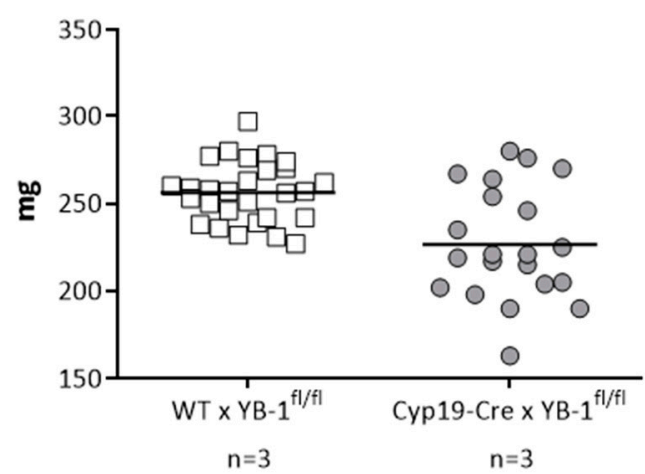

Figure 7. Significantly decreased placental weights in in YB-1 1 l/fll-mated Cyp19-Cre females compared to YB-1 ${ }^{\mathrm{fl} / \mathrm{fl}}$-mated WT females at GD12 and 14. Placental weights $(\mathbf{A}, \mathbf{B})$ and fetal weights $(\mathbf{C}, \mathbf{D})$ from progeny of Cyp19-Cre $\times$ YB-1 $1^{\mathrm{fl} / \mathrm{fl}}(n=3-7)$ or WT $\times$ YB-1 $1^{\mathrm{f} / \mathrm{fl}}(n=3-9)$ matings are shown at GD12 and 14. Data is presented as means showing individual values for each placenta/fetus. Statistical differences were determined by using a mixed linear model using the final test principle $\left.{ }^{*} p<0.05\right)$.

\section{Discussion}

A myriad of functions have been attributed to YB-1. Among these, YB-1 plays a major role in cancer development and progression due to its ability to support the proliferation, invasion and metastasis of various tumor cells [12,25-27]. Moreover, this cold shock protein is also relevant for the regulation of inflammatory responses due to the transcriptional and translational regulation of inflammatory mediators [28-30]. Previous data by Lu and colleagues as well as Uchiumi and colleagues also strongly suggest that YB-1 may be relevant for pregnancy outcome or fetal wellbeing $[8,9]$. YB-1 HET intercrossings resulted in a significant growth retardation in YB-1-deficient fetuses when compared to their YB-1-half-sufficient and -sufficient littermates from mid-gestation onwards. YB-1 KO fetuses showed severe malformations in different organ systems and eventually died perinatally $[8,9]$. As the nonviability of YB-1 KO progeny hinders experiments employing homozygous intercrossing combinations, we paired YB-1 heterozygous mice and compared fetal and maternal parameters with those of YB-1 WT matings. Our results strongly suggest that YB-1 absence does not interfere with the ability of the embryos to implant into the maternal endometrium. Obviously, embryonic lethality seems to be restricted to later gestational time points, as proposed in previous studies [8,9]. However, this does not rule out the possibility that YB-1 affects early pregnancy mechanisms whose readout appears later and derives from fetal impairment.

Despite an apparently undisturbed implantation, fetal weights were reduced in YB-1 HET mating combinations when compared to YB-1 WT controls at GD14. Moreover, we detected significant smaller implantation areas in YB-1 HET combinations compared to YB-1 WT controls already at GD10. As our 
intention was to follow up implantation areas, placental parameters and uterine flow parameters in the same pregnant mouse from GD5 to GD14 by sequential ultrasound measurements, in this set of experiments, we did not sacrifice mice earlier than GD14. This kind of analysis impeded the genotypic determination of the individual implantations at GD10. Thus, we assume that implantations of significantly reduced size are the ones completely lacking YB-1, and further evaluations are required to confirm this assumption. As YB-1 expression is strong in trophoblasts, we next followed the strategy of generating trophoblast-specific YB-1-deficient mice.

Fetal growth mainly depends on adequate placental development and function, which are usually reflected in placental size, shape and histological structure. Consequently, impairments in placental development resulting in decreased placental surface areas, decreased placental diameters and decreased placental weights are associated with fetal growth retardation [31-33] and usually lead to adverse pregnancy outcomes or fetal/neonatal perinatal mortality and morbidity. We assessed placental parameters at different GDs and found a significant upregulation in the placental diameter/thickness ratios as well as a significant downregulation in the placental weights in YB-1 HET matings compared to YB-1 WT matings at GD14. Given the fact that placental disc thickness marks the extent of the maternal fetal exchange area, an increased placental diameter/thickness ratio because of a decreased placental thickness is indicative for fetal malnutrition and thus a lower birth weight [34]. Moreover, small placental areas and low placental weights are usually associated with higher uterine PI and RI [35] that may result in reduced placental perfusion and subsequently in insufficient nutrient supply to the fetus. Therefore, we analyzed uterine flow parameters by high-frequency ultrasound during pregnancy. Although in our experimental settings, uterine flow parameters were not altered in YB-1 HET matings, histological analysis of SA remodeling parameters displayed a picture of inadequate SA remodeling. Placentas from heterozygote mating combinations had increased, thus disturbed, SA wall-to-lumen ratios. Causative for this insufficient SA remodeling process are often perturbed mechanisms from both the maternal and the fetal side. Hence, in addition to a potential contribution of maternal YB-1 to the SA remodeling process, we assumed that poor trophoblast function characterized by the inability of these cells to proliferate, migrate and/or invade the arteries may be responsible for the observed phenotype [36]. Thus, we wondered whether a specific ablation of YB-1 in trophoblast cells would similarly affect fetal and placental outcomes as observed in the YB-1 HET intercrossings. To study a trophoblast-specific deletion of YB-1, we generated Cyp19Cre/YB-1 $1^{\mathrm{fl} / \mathrm{fl}}$ mice, whose placentas are YB-1-deficient. In the Cyp19Cre mice, the Cre transgene is driven by placenta-specific regulatory sequences from the human Cyp19 gene. Cre expression was confirmed in trophoblast stem cells in the extraembryonic ectoderm and the ectoplacental cone at E6.5 and E8.5 [37]. Several research groups have used Cyp19Cre mice for the placenta-specific deletion of distinct genes to study their participation in placenta formation and pregnancy outcomes [38-41]. However, all placentas still contained one YB-1 WT allele, resulting in a reduction of placental YB-1 expression by $50 \%$. This is in accordance with results obtained by a study in which the authors used Cyp19Cre/IL-6R $\alpha$ mice to specifically delete IL-6R $\alpha$ in the placenta. mRNA and protein expression analyses revealed a $50 \%$ reduction of placental IL-6R $\alpha$ [42]. After placenta-specific knockdown of YB-1, impairments in fetal and placental parameters occurred even earlier than in YB-1 HET mating combinations. Significant reductions in implantations areas were already visible at GD8, and the first signs of altered placental parameters were evident from GD10 onwards. Unexpectedly, fetal weights were not significantly diminished after placenta-specific YB-1 ablation at GD14, which contrasts with our observations made in YB-1 HET combinations. This might be explained by the fact that fetuses of Cyp19Cre/YB-1 $1^{\mathrm{fl} / \mathrm{fl}}$ matings are not directly affected by placental YB-1 knockdown and significantly reduced fetal weights in YB-1 HET matings are the consequence of missing YB-1 in the placenta and in the fetus. Moreover, we have to admit that in our mating combination, a complete absence of YB-1 in the placenta could not be achieved, and this might also explain the insignificant diminution in fetal weights. In accordance with our results obtained in YB-1 HET matings, the number of implantations and abortion rates was similar in Cyp19Cre/YB-1 ${ }^{\mathrm{fl} / \mathrm{fl}}$ matings. 
Data on cold shock proteins in general and YB-1 in particular are scarce for the field of placentation, and until now, we could only speculate about YB-1-driven mechanisms in placentation. Extracellular YB-1 was proven to serve as a noncanonical ligand for receptor Notch-3 [43], and a role for Notch3 signaling in trophoblast migration and invasion was suggested [44,45]. Further research is needed to confirm YB-1 autocrine effects on trophoblast function through this pathway. As trophoblast cells and cancer cells share common functional features, including their potential to proliferate, migrate, invade, and to induce vascularization [46], we firmly believe that YB-1 is an interesting candidate to follow up in the research area of pregnancy and more precisely for the events around placentation. Our data show that whole-body heterozygous mice combination results in impaired placentation and fetal growth. A more elegant approach employing trophoblast-specific YB-1 knock-down refines the finding by showing suboptimal developed placentas. In cancer cells, YB-1 has been shown to activate the expression of several genes important for cell proliferation, such as DNA polymerase $\alpha$, cyclins, PIK3CA, EGFR and HER-2 [47], with some of these molecules being implicated in trophoblast proliferation [48-50]. Furthermore, YB-1 promotes cancer migration and invasion by activating the metalloproteinases MMP2 and MT1 [17,18]. MMPs are well known for their participation in trophoblast-mediated functions [51], and we propose that YB-1 supports placentation through the modulation of MMPs. Finally, YB-1 might also play a critical role for placentation-associated angiogenesis by inducing the expression of proangiogenic genes [47,52]. However, the involvement of YB-1 in these placentation pathways remains speculative and is the focus of ongoing studies.

\section{Conclusions}

In summary, our data show the importance of YB-1 for intrauterine embryonic/fetal and placental development from early gestational stages. Moreover, our study provides the first evidence for the relevance of trophoblast-specific YB-1 to placentation. Future studies will dissect the underlying pathways and determine whether these pathways are relevant for patients whose babies are born growth-retarded.

Supplementary Materials: The following are available online at http://www.mdpi.com/2073-4409/9/9/1942/s1, Figure S1: Representative 2D greyscale ultrasound image of one implantation site showing placental area, diameter and thickness; Figure S2: No alterations of uterine artery (UA) flow parameters in $\mathrm{YB}^{-1} 1^{+/}$females compared to $\mathrm{YB}-1^{+/+}$females at GD10, 12 and 14; Figure S3: No alterations of uterine artery (UA) flow parameters in YB-1 ${ }^{\mathrm{fl} / \mathrm{fl}}$-mated Cyp19-Cre females compared to YB-1 $1^{\mathrm{fl} / \mathrm{fl}}$-mated WT females at GD5, 8, 10, 12 and 14.

Author Contributions: Conceptualization: A.C.Z.; methodology, N.M. and A.S.; validation, N.M., A.S. and A.C.Z.; formal analysis, U.C.; investigation, U.C, K.W. and H.S.; resources, P.R.M. and A.C.Z.; data curation, U.C.; writing —original draft preparation, A.S. and N.M.; writing-review and editing, P.R.M., J.A.L. and A.C.Z.; visualization, U.C., N.M. and A.S.; supervision, A.C.Z.; project administration, A.S.; funding acquisition, A.C.Z. All authors have read and agreed to the published version of the manuscript.

Funding: This research was funded by the German Research Foundation to A.C.Z., under grant number ZE 526/14-1, and in a lesser extent to P.R.M., under grant number SFB 854, Project A1.

Acknowledgments: We are thankful to Gustavo Leone who generously provided the Cre mice to generate trophoblast-specific YB-1 mice. We are grateful to Stefanie Langwisch, who was in charge of the mouse colonies, and Markus Scharm, for his skilled technical assistance.

Conflicts of Interest: The authors declare no conflict of interest.

\section{References}

1. Lindquist, J.A.; Mertens, P.R. Cold shock proteins: From cellular mechanisms to pathophysiology and disease. Cell Commun. Signal 2018, 16, 63. [CrossRef] [PubMed]

2. Frye, B.C.; Halfter, S.; Djudjaj, S.; Muehlenberg, P.; Weber, S.; Raffetseder, U.; En-Nia, A.; Knott, H.; Baron, J.M.; Dooley, S.; et al. Y-box protein-1 is actively secreted through a non-classical pathway and acts as an extracellular mitogen. EMBO Rep. 2009, 10, 783-789. [CrossRef] [PubMed] 
3. Guarino, A.M.; Troiano, A.; Pizzo, E.; Bosso, A.; Vivo, M.; Pinto, G.; Amoresano, A.; Pollice, A.; La Mantia, G.; Calabro, V. Oxidative Stress Causes Enhanced Secretion of YB-1 Protein that Restrains Proliferation of Receiving Cells. Genes 2018, 9. [CrossRef] [PubMed]

4. Kwon, E.J.; Kim, Y.J. What is fetal programming? A lifetime health is under the control of in utero health. Obstet. Gynecol. Sci. 2017, 60, 506-519. [CrossRef]

5. Gluckman, P.D.; Hanson, M.A.; Cooper, C.; Thornburg, K.L. Effect of in utero and early-life conditions on adult health and disease. N. Engl. J. Med. 2008, 359, 61-73. [CrossRef]

6. Budkina, K.S.; Zlobin, N.E.; Kononova, S.V.; Ovchinnikov, L.P.; Babakov, A.V. Cold Shock Domain Proteins: Structure and Interaction with Nucleic Acids. Biochemistry (Moscow) 2020, 85, S1-S19. [CrossRef]

7. Shibahara, K.; Uchiumi, T.; Fukuda, T.; Kura, S.; Tominaga, Y.; Maehara, Y.; Kohno, K.; Nakabeppu, Y.; Tsuzuki, T.; Kuwano, M. Targeted disruption of one allele of the Y-box binding protein-1 (YB-1) gene in mouse embryonic stem cells and increased sensitivity to cisplatin and mitomycin C. Cancer Sci. 2004, 95, 348-353. [CrossRef]

8. Uchiumi, T.; Fotovati, A.; Sasaguri, T.; Shibahara, K.; Shimada, T.; Fukuda, T.; Nakamura, T.; Izumi, H.; Tsuzuki, T.; Kuwano, M.; et al. YB-1 is important for an early stage embryonic development: Neural tube formation and cell proliferation. J. Biol. Chem. 2006, 281, 40440-40449. [CrossRef]

9. Lu, Z.H.; Books, J.T.; Ley, T.J. YB-1 is important for late-stage embryonic development, optimal cellular stress responses, and the prevention of premature senescence. Mol. Cell Biol. 2005, 25, 4625-4637. [CrossRef]

10. Lu, Z.H.; Books, J.T.; Ley, T.J. Cold shock domain family members YB-1 and MSY4 share essential functions during murine embryogenesis. Mol. Cell Biol. 2006, 26, 8410-8417. [CrossRef]

11. Basaki, Y.; Taguchi, K.; Izumi, H.; Murakami, Y.; Kubo, T.; Hosoi, F.; Watari, K.; Nakano, K.; Kawaguchi, H.; Ohno, S.; et al. Y-box binding protein-1 (YB-1) promotes cell cycle progression through CDC6-dependent pathway in human cancer cells. Eur. J. Cancer 2010, 46, 954-965. [CrossRef] [PubMed]

12. Maurya, P.K.; Mishra, A.; Yadav, B.S.; Singh, S.; Kumar, P.; Chaudhary, A.; Srivastava, S.; Murugesan, S.N.; Mani, A. Role of Y Box Protein-1 in cancer: As potential biomarker and novel therapeutic target. J. Cancer 2017, 8, 1900-1907. [CrossRef] [PubMed]

13. Astanehe, A.; Finkbeiner, M.R.; Hojabrpour, P.; To, K.; Fotovati, A.; Shadeo, A.; Stratford, A.L.; Lam, W.L.; Berquin, I.M.; Duronio, V.; et al. The transcriptional induction of PIK3CA in tumor cells is dependent on the oncoprotein Y-box binding protein-1. Oncogene 2009, 28, 2406-2418. [CrossRef] [PubMed]

14. Lim, J.P.; Shyamasundar, S.; Gunaratne, J.; Scully, O.J.; Matsumoto, K.; Bay, B.H. YBX1 gene silencing inhibits migratory and invasive potential via CORO1C in breast cancer in vitro. BMC Cancer 2017, 17, 201. [CrossRef]

15. Chatterjee, M.; Rancso, C.; Stuhmer, T.; Eckstein, N.; Andrulis, M.; Gerecke, C.; Lorentz, H.; Royer, H.D.; Bargou, R.C. The Y-box binding protein YB-1 is associated with progressive disease and mediates survival and drug resistance in multiple myeloma. Blood 2008, 111, 3714-3722. [CrossRef]

16. Lee, C.; Dhillon, J.; Wang, M.Y.; Gao, Y.; Hu, K.; Park, E.; Astanehe, A.; Hung, M.C.; Eirew, P.; Eaves, C.J.; et al. Targeting YB-1 in HER-2 overexpressing breast cancer cells induces apoptosis via the mTOR/STAT3 pathway and suppresses tumor growth in mice. Cancer Res. 2008, 68, 8661-8666. [CrossRef]

17. Mertens, P.R.; Alfonso-Jaume, M.A.; Steinmann, K.; Lovett, D.H. A synergistic interaction of transcription factors AP2 and YB-1 regulates gelatinase A enhancer-dependent transcription. J. Biol. Chem. 1998, 273, 32957-32965. [CrossRef]

18. Lovett, D.H.; Cheng, S.; Cape, L.; Pollock, A.S.; Mertens, P.R. YB-1 alters MT1-MMP trafficking and stimulates MCF-7 breast tumor invasion and metastasis. Biochem. Biophys. Res. Commun. 2010, 398, 482-488. [CrossRef]

19. Ding, R.; Liu, X.M.; Xiang, Y.Q.; Zhang, Y.; Zhang, J.Y.; Guo, F.; Liu, Z.W.; Fan, J.X. Altered Matrix Metalloproteinases Expression in Placenta from Patients with Gestational Diabetes Mellitus. Chin. Med. J. 2018, 131, 1255-1258. [CrossRef]

20. Hiden, U.; Ghaffari-Tabrizi, N.; Gauster, M.; Tam-Amersdorfer, C.; Cetin, I.; Dieber-Rotheneder, M.; Lang, U.; Desoye, G. Membrane-type matrix metalloproteinase 1 regulates trophoblast functions and is reduced in fetal growth restriction. Am. J. Pathol. 2013, 182, 1563-1571. [CrossRef]

21. Meyer, N.; Woidacki, K.; Knofler, M.; Meinhardt, G.; Nowak, D.; Velicky, P.; Pollheimer, J.; Zenclussen, A.C. Chymase-producing cells of the innate immune system are required for decidual vascular remodeling and fetal growth. Sci. Rep. 2017, 7, 45106. [CrossRef] [PubMed] 
22. Meyer, N.; Schuler, T.; Zenclussen, A.C. Simultaneous Ablation of Uterine Natural Killer Cells and Uterine Mast Cells in Mice Leads to Poor Vascularization and Abnormal Doppler Measurements That Compromise Fetal Well-being. Front Immunol. 2017, 8, 1913. [CrossRef] [PubMed]

23. Meyer, N.; Schuler, T.; Zenclussen, A.C. High Frequency Ultrasound for the Analysis of Fetal and Placental Development In Vivo. J. Vis. Exp. 2018, 141. [CrossRef] [PubMed]

24. Whitley, G.S.; Cartwright, J.E. Cellular and molecular regulation of spiral artery remodelling: Lessons from the cardiovascular field. Placenta 2010, 31, 465-474. [CrossRef]

25. Ferreira, A.R.; Bettencourt, M.; Alho, I.; Costa, A.L.; Sousa, A.R.; Mansinho, A.; Abreu, C.; Pulido, C.; Macedo, D.; Vendrell, I.; et al. Serum YB-1 (Y-box binding protein 1) as a biomarker of bone disease progression in patients with breast cancer and bone metastases. J. Bone Oncol. 2017, 6, 16-21. [CrossRef]

26. Johnson, T.G.; Schelch, K.; Mehta, S.; Burgess, A.; Reid, G. Why Be One Protein When You Can Affect Many? The Multiple Roles of YB-1 in Lung Cancer and Mesothelioma. Front Cell Dev. Biol. 2019, 7, 221. [CrossRef]

27. Lasham, A.; Print, C.G.; Woolley, A.G.; Dunn, S.E.; Braithwaite, A.W. YB-1: Oncoprotein, prognostic marker and therapeutic target? Biochem. J. 2013, 449, 11-23. [CrossRef]

28. Hanssen, L.; Alidousty, C.; Djudjaj, S.; Frye, B.C.; Rauen, T.; Boor, P.; Mertens, P.R.; van Roeyen, C.R.; Tacke, F.; Heymann, F.; et al. YB-1 is an early and central mediator of bacterial and sterile inflammation in vivo. J. Immunol. 2013, 191, 2604-2613. [CrossRef]

29. Raffetseder, U.; Liehn, E.A.; Weber, C.; Mertens, P.R. Role of cold shock Y-box protein-1 in inflammation, atherosclerosis and organ transplant rejection. Eur. J. Cell Biol. 2012, 91, 567-575. [CrossRef]

30. Wang, J.; Djudjaj, S.; Gibbert, L.; Lennartz, V.; Breitkopf, D.M.; Rauen, T.; Hermert, D.; Martin, I.V.; Boor, P.; Braun, G.S.; et al. YB-1 orchestrates onset and resolution of renal inflammation via IL10 gene regulation. J. Cell Mol. Med. 2017, 21, 3494-3505. [CrossRef]

31. Almasry, S.M.; Elfayomy, A.K. Morphometric analysis of terminal villi and gross morphological changes in the placentae of term idiopathic intrauterine growth restriction. Tissue Cell 2012, 44, 214-219. [CrossRef] [PubMed]

32. Egbor, M.; Ansari, T.; Morris, N.; Green, C.J.; Sibbons, P.D. Pre-eclampsia and fetal growth restriction: How morphometrically different is the placenta? Placenta 2006, 27, 727-734. [CrossRef] [PubMed]

33. Mayhew, T.M.; Manwani, R.; Ohadike, C.; Wijesekara, J.; Baker, P.N. The placenta in pre-eclampsia and intrauterine growth restriction: Studies on exchange surface areas, diffusion distances and villous membrane diffusive conductances. Placenta 2007, 28, 233-238. [CrossRef] [PubMed]

34. Salafia, C.M.; Zhang, J.; Charles, A.K.; Bresnahan, M.; Shrout, P.; Sun, W.; Maas, E.M. Placental characteristics and birthweight. Paediatr. Perinat. Epidemiol. 2008, 22, 229-239. [CrossRef]

35. Salavati, N.; Sovio, U.; Mayo, R.P.; Charnock-Jones, D.S.; Smith, G.C. The relationship between human placental morphometry and ultrasonic measurements of utero-placental blood flow and fetal growth. Placenta 2016, 38, 41-48. [CrossRef]

36. Meyer, N.; Zenclussen, A.C. Immune Cells in the Uterine Remodeling: Are They the Target of Endocrine Disrupting Chemicals? Front Immunol. 2020, 11, 246. [CrossRef]

37. Wenzel, P.L.; Leone, G. Expression of Cre recombinase in early diploid trophoblast cells of the mouse placenta. Genesis 2007, 45, 129-134. [CrossRef]

38. Lu, J.; Wu, W.; Xin, Q.; Zhou, C.; Wang, J.; Ni, Z.; Liu, D.; Xu, Y.; Yu, Y.; Yang, N.; et al. Spatiotemporal coordination of trophoblast and allantoic Rbpj signaling directs normal placental morphogenesis. Cell Death Dis. 2019, 10, 438. [CrossRef]

39. Ouseph, M.M.; Li, J.; Chen, H.Z.; Pecot, T.; Wenzel, P.; Thompson, J.C.; Comstock, G.; Chokshi, V.; Byrne, M.; Forde, B.; et al. Atypical E2F repressors and activators coordinate placental development. Dev. Cell 2012, 22, 849-862. [CrossRef]

40. Shawber, C.J.; Brown-Grant, D.A.; Wu, T.; Kitajewski, J.K.; Douglas, N.C. Dominant-negative inhibition of canonical Notch signaling in trophoblast cells does not disrupt placenta formation. Biol. Open 2019, 8. [CrossRef]

41. Wenzel, P.L.; Wu, L.; de Bruin, A.; Chong, J.L.; Chen, W.Y.; Dureska, G.; Sites, E.; Pan, T.; Sharma, A.; Huang, K.; et al. Rb is critical in a mammalian tissue stem cell population. Genes Dev. 2007, 21, 85-97. [CrossRef] [PubMed]

42. Wu, W.L.; Hsiao, E.Y.; Yan, Z.; Mazmanian, S.K.; Patterson, P.H. The placental interleukin-6 signaling controls fetal brain development and behavior. Brain Behav. Immun. 2017, 62, 11-23. [CrossRef] [PubMed] 
43. Rauen, T.; Raffetseder, U.; Frye, B.C.; Djudjaj, S.; Muhlenberg, P.J.; Eitner, F.; Lendahl, U.; Bernhagen, J.; Dooley, S.; Mertens, P.R. YB-1 acts as a ligand for Notch-3 receptors and modulates receptor activation. J. Biol. Chem. 2009, 284, 26928-26940. [CrossRef] [PubMed]

44. Zhao, W.-X.; Zhuang, X.; Huang, T.-T.; Feng, R.; Lin, J.-H. Effects of Notch2 and Notch3 on Cell Proliferation and Apoptosis of Trophoblast Cell Lines. Int. J. Med. Sci. 2015, 12, 867-874. [CrossRef]

45. Zhao, W.-X.; Wu, Z.-M.; Liu, W.; Lin, J.-H. Notch2 and Notch3 suppress the proliferation and mediate invasion of trophoblast cell lines. Biol. Open 2017, 6, 1123-1129. [CrossRef]

46. West, R.C.; Bouma, G.J.; Winger, Q.A. Shifting perspectives from "oncogenic" to oncofetal proteins; how these factors drive placental development. Reprod. Biol. Endocrinol. 2018, 16, 101. [CrossRef]

47. Kosnopfel, C.; Sinnberg, T.; Schittek, B. Y-box binding protein 1-a prognostic marker and target in tumour therapy. Eur. J. Cell Biol. 2014, 93, 61-70. [CrossRef]

48. DeLoia, J.A.; Burlingame, J.M.; Krasnow, J.S. Differential expression of G1 cyclins during human placentogenesis. Placenta 1997, 18, 9-16. [CrossRef]

49. Fock, V.; Plessl, K.; Fuchs, R.; Dekan, S.; Milla, S.K.; Haider, S.; Fiala, C.; Knofler, M.; Pollheimer, J. Trophoblast subtype-specific EGFR/ERBB4 expression correlates with cell cycle progression and hyperplasia in complete hydatidiform moles. Hum. Reprod. 2015, 30, 789-799. [CrossRef]

50. Ferretti, C.; Bruni, L.; Dangles-Marie, V.; Pecking, A.P.; Bellet, D. Molecular circuits shared by placental and cancer cells, and their implications in the proliferative, invasive and migratory capacities of trophoblasts. Hum. Reprod. Update 2007, 13, 121-141. [CrossRef]

51. Li, J.; Zhao, T.; Duan, E. Matrix metalloproteinases (MMPs) and trophoblast invasion. Chin. Sci. Bulletin 2005, 50, 1169-1173. [CrossRef]

52. Gopal, S.K.; Greening, D.W.; Mathias, R.A.; Ji, H.; Rai, A.; Chen, M.; Zhu, H.-J.; Simpson, R.J. YBX1/YB-1 induces partial EMT and tumourigenicity through secretion of angiogenic factors into the extracellular microenvironment. Oncotarget 2015, 6, 13718-13730. [CrossRef] [PubMed]

(C) 2020 by the authors. Licensee MDPI, Basel, Switzerland. This article is an open access article distributed under the terms and conditions of the Creative Commons Attribution (CC BY) license (http://creativecommons.org/licenses/by/4.0/). 